\title{
Papers
}

\section{Risk factors, prevalence, and treatment of anxiety and depressive disorders in Pakistan: systematic review}

Ilyas Mirza, Rachel Jenkins

\begin{abstract}
Objectives To assess the available evidence on the prevalence, aetiology, treatment, and prevention of anxiety and depressive disorders in Pakistan.

Design Systematic review of published literature.

Studies reviewed 20 studies, of which 17 gave prevalence estimates and 11 discussed risk factors.

Main outcome measures Prevalence of anxiety and depressive disorders, risk factors, effects of treatment.

Results Factors positively associated with anxiety and depressive disorders were female sex, middle age, low level of education, financial difficulty, being a housewife, and relationship problems. Arguments with husbands and relational problems with in-laws were positively associated in 3/11 studies. Those who had close confiding relationships were less likely to have anxiety and depressive disorders. Mean overall prevalence of anxiety and depressive disorders in the community population was $34 \%$ (range $29-66 \%$ for women and $10-33 \%$ for men). There were no rigorously controlled trials of treatments for these disorders.

Conclusions Available evidence suggests a major social cause for anxiety and depressive disorders in Pakistan. This evidence is limited because of methodological problems, so caution must be exercised in generalising this to the whole of the population of Pakistan.
\end{abstract}

\section{Introduction}

Anxiety and depressive disorders are common in all regions of the world. ${ }^{1}$ They constitute a substantial proportion of the global burden of disease, and are projected to form the second most common cause of disability by $2020 .^{2}$ This increased importance of non-communicable diseases such as anxiety and depressive disorders presents a particular challenge for low income countries, where infectious diseases and malnutrition are still rife and where only a low percentage of gross domestic product is allocated to health services. ${ }^{3}$ These disorders are also important because of their economic consequences. ${ }^{4}$

With an estimated population of 152 million, Pakistan is the sixth most populous country in the world. It is projected that, by 2050, the population will have increased to make it the fourth most populous country. There is a need to develop an evidence base to aid policy development on tackling anxiety and depressive disorders. We therefore conducted a systematic review as no such work existed to our knowledge.

Our main questions were $(a)$ what the estimated prevalence of anxiety and depressive disorders is in Pakistan and how this compares with estimates from other low income countries; (b) what the associated social, psychological, and biological factors are; and $(c)$ what evidence exists for effectiveness of treatment or prevention in this population.

\section{Methods}

Data sources

Using the key words "Pakistan" and ("mental" or "depression" or "anxiety" or "psychiatric"), we searched the following bibliographic databases from the start of each of their time frames: Applied Social Sciences Index and Abstracts, Cumulative Index to Nursing and Allied Health, Cochrane Trials Register, Excerpta Medica, National Library of Medicine Gateway, Medline (Pubmed), PsycINFO, Science Citation Index, and Social Science Citation Index. We searched the reference lists of retrieved articles for relevant studies. We also searched Pakmedinet.com, a medical website. These searches were last repeated on 1 March 2002 to keep the review as current as possible. Additionally, we hand searched the Pakistan Journal of Clinical Psychiatry until 1995, when it ceased publication.

\section{Study selection}

We selected studies that were conducted within Pakistan and that focused on depression, depressive disorder, or anxiety disorder in adults (ages 18-65). Variables of interest were prevalence, vulnerability factors, protective factors, and effectiveness of treatment and prevention strategies.

\section{Data extraction}

Each study received a code based on the relevance of its abstract and title to the study questions. Studies or reviews directly addressing anxiety and depressive disorders were retrieved for data extraction. Potentially useful qualitative and quantitative studies, as well as review articles were also retrieved. (A complete list is available from the authors.)

\section{Validity check}

We assessed the methodological quality of the selected studies according to hierarchies of evidence and critical appraisal checklists. ${ }^{6}$ Since relatively few studies addressed our study questions, we included all studies directly relevant to the questions regardless of their quality.

\section{Study synthesis}

A narrative synthesis of the extracted studies was performed to address the questions of the review.

References w1-w20 are listed on bmj.com

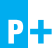




\section{Results}

We found 20 studies that directly addressed the questions of the review: 19 were cross sectional epidemiological surveys, and one was a case-control study. ${ }^{\mathrm{w}-\mathrm{w} 20}$ Seventeen gave prevalence estimates $(\mathrm{n}=9170)$, while 11 discussed associated risk factors. We did not find any prospective study of the natural course of the disorder or a rigorously controlled study of any interventions. We found little qualitative work. Sample sizes ranged from 113 to 2620 in prevalence studies (mean 539.41, median 298).

\section{Methods of included studies}

Table 1 shows the methodological quality of the studies. Only three of the 11 prevalence studies published in local journals gave adequate details of methods. Because of this, it is difficult to comment on possible biases. Even when basic data were provided it is questionable how representative the study sample was of the population. ${ }^{7}$ Diagnoses in all the studies were made by either a psychiatrist or a trained worker using a validated instrument, and thus seem to be of reasonably good quality.

Most of the studies discussed the generalisability of their findings but did not interpret any null findings. In the discussions, national comparisons were rarely made with findings of other national research groups; comparisons were usually with studies in other countries.

\section{Prevalence of anxiety and depressive disorders}

Table 2 lists the prevalence of anxiety and depressive disorders estimated in the studies. The overall mean prevalence in men and women in the six studies of random community samples $(\mathrm{n}=2658)$ was $33.62 \%$, with the point prevalence varying from $28.8 \%$ to $66 \%$ for women (overall mean $45.5 \%$ ) and from $10 \%$ to $33 \%$ for men (overall mean 21.7\%). Women aged 15-49 were studied in a paper with $28.8 \%$ prevalence, while young men with a mean age of 18 participated in a study reporting 33\% prevalence. Only one study reported adjusted prevalence with $95 \%$ confidence intervals.

For those presenting to traditional or faith healers $(n=511)$, the prevalence of anxiety and depressive disorders among men varied from $2.65 \%$ to $27 \%$, and among women from $11.5 \%$ to $52 \%$.

Three studies looked at total psychiatric morbidity in primary care $(\mathrm{n}=774)$. One described women in a rural area, with a prevalence of $50 \%$, while another described $18 \%$ prevalence for men and $42.2 \%$ for women in an urban area. The third study, with a prevalence of $38.4 \%$, did not specify participants' sex.

Of those presenting to psychiatric outpatients $(n=2430)$, the prevalence varied between $32 \%$ and $66.3 \%$. There were two studies on psychiatric inpatients, one reported a prevalence of depressive illness of $37 \%(n=2620)$, while the other reported $19.1 \%(n=177)$.

\section{Associated social, psychological, and biological factors}

Table 3 shows the various factors found to be associated with anxiety and depressive disorders. Sociodemographic factors associated with increased prevalence of anxiety and depressive disorders were female sex, middle age, and low level of education. Loss of husband (being widowed, separated, or divorced), increasing duration of marriage, and being a housewife were also positively associated. Women living in joint households with more than 12 members also showed a positive association; in contrast, one study reported a positive association for women living in unitary households. One study showed a positive significant association for relational problems with in-laws for women compared with other social problems. Chronic difficulties with housing, finances, and health were significantly associated with anxiety and depressive disorders. Absence of a confiding relationship was a significant factor in one study, as were lack of autonomy and arguments with husbands and in-laws in another. A disturbing event in the family was not significantly associated $(\mathrm{P}=0.08)$.

Factors perceived by women to be associated with mental distress were low family income, marital disputes, too many children, and verbal abuse by in-laws. Studies that incorporated income found financial difficulties to be a significant factor, except for one study, in which the finding was just non-significant $(\mathrm{P}=0.06)$.

Table 1 Checklist for quality of studies included in systematic review of evidence on prevalence, aetiology, treatment, and prevention of anxiety and depressive disorders in Pakistan

\begin{tabular}{|c|c|c|c|c|c|c|c|c|c|c|}
\hline Study & $\begin{array}{l}\text { Explicit } \\
\text { aims }\end{array}$ & $\begin{array}{l}\text { Sample size } \\
\text { justification } \\
\text { or adequate }\end{array}$ & $\begin{array}{c}\text { Justification } \\
\text { sample } \\
\text { representative } \\
\text { of population }\end{array}$ & $\begin{array}{l}\text { Inclusion and } \\
\text { exclusion } \\
\text { criteria stated }\end{array}$ & $\begin{array}{c}\text { Reliability } \\
\text { and validity of } \\
\text { measures } \\
\text { justified }\end{array}$ & $\begin{array}{l}\text { Response rate } \\
\text { and drop out } \\
\text { specified }\end{array}$ & $\begin{array}{c}\text { Data } \\
\text { adequately } \\
\text { described }\end{array}$ & $\begin{array}{l}\text { Statistical } \\
\text { significance } \\
\text { assessed }\end{array}$ & $\begin{array}{c}\text { Discussion of } \\
\text { generalisability }\end{array}$ & $\begin{array}{l}\text { Null findings } \\
\text { interpreted }\end{array}$ \\
\hline Ali et al $1993^{w 1}$ & Yes & Yes & No & In part & Yes & Yes & No & Yes & No & No \\
\hline Ali et al $2000^{w 2}$ & Yes & Yes & Yes & In part & Yes & Yes & No & Yes & Yes & No \\
\hline Bender $2001^{w 3}$ & Yes & Yes & Yes & Yes & Yes & Yes & Yes & Yes & Yes & Yes \\
\hline Dodani et al $2000^{w 4}$ & Yes & No & No & In part & Yes & Yes & No & Yes & Yes & No \\
\hline Gadit et al $1998^{\mathrm{w} 5}$ & Yes & Yes & No & Yes & Yes & Yes & Yes & NA & Yes & NA \\
\hline Gadit $2001^{w 6}$ & Yes & Yes & No & Yes & Yes & Yes & In part & NA & Yes & NA \\
\hline Hussain et al $2000^{\text {w7 }}$ & Yes & Yes & Yes & Yes & Yes & Yes & Yes & Yes & Yes & Yes \\
\hline Javed et al $1991^{\text {w8 }}$ & Yes & No & No & Yes & Yes & NA & No & No & No & No \\
\hline Javed 1994" & Yes & No & No & In part & Yes & NA & No & No & Yes & No \\
\hline Malik et al $1999^{w 10}$ & Yes & Yes & Yes & Yes & Yes & NA & Yes & NA & Yes & NA \\
\hline Malik et al $2000^{\text {w/11 }}$ & Yes & NA & NA & NA & Yes & NA & No & NA & NA & NA \\
\hline Minhas et al $2001^{w 12}$ & Yes & Yes & Yes & Yes & Yes & NA & In part & NA & Yes & NA \\
\hline Mumford et al $1996^{\text {w13 }}$ & Yes & Yes & Yes & Yes & Yes & Yes & Yes & Yes & Yes & Yes \\
\hline Mumford et al $1997^{\mathrm{w} 14}$ & Yes & Yes & Yes & Yes & Yes & Yes & Yes & Yes & Yes & Yes \\
\hline Mumford et al $2000^{\text {w15 }}$ & Yes & Yes & Yes & Yes & Yes & Yes & Yes & Yes & Yes & Yes \\
\hline Naeem 1992 $2^{\text {w16 }}$ & Yes & No & No & Yes & No & NA & In part & Yes & No & Yes \\
\hline Rabbani 1999w17 & Yes & NA & Yes & In part & NA & Yes & Yes & NA & In part & NA \\
\hline Rabbani et al 2000w18 & Yes & Yes & Yes & Yes & Yes & Yes & No & Yes & Yes & Yes \\
\hline Saeed et al $2000^{\text {w19 }}$ & Yes & No & No & In part & Yes & Yes & In part & NA & No & NA \\
\hline Saeed et al $2000^{w 20}$ & Yes & No & No & In part & Yes & Yes & No & Yes & No & No \\
\hline
\end{tabular}

$\mathrm{NA}=$ Not applicable. 
Table 2 Details of studies included in systematic review with prevalence estimates of anxiety and depressive disorders

\begin{tabular}{|c|c|c|c|c|}
\hline Study & Study type & $\begin{array}{l}\text { No of participants (sexes), } \\
\text { age range (years) }\end{array}$ & Outcome measures & Prevalence $(95 \% \mathrm{Cl})$ \\
\hline \multicolumn{5}{|l|}{ Rural setting } \\
\hline \multicolumn{5}{|l|}{ Population based sample: } \\
\hline Hussain et al $2000^{w 7}$ & Prospective two stage survey & 259 (both), $\geq 18$ & $\begin{array}{l}\text { PHQ cut-off }>5, \text { SRQ }>8, \text { PAS ID } \\
\text { level }>4 \text {, LEDS }\end{array}$ & $\begin{array}{l}\text { AP of } A+D=44.4 \% \text { ( } 35.3 \text { to } 53.6) \text {. } \\
P=57.5 \% \text { (women), } 25.5 \% \text { (men) }\end{array}$ \\
\hline Mumford et al $1996^{w 13}$ & Prospective two stage survey & 515 (both), $\geq 18$ & BSI-21 cut-off $>20$, ICD 10R & $\begin{array}{l}\text { PP of } A+D \text { (using BSI-21)=15\% } \\
\text { (men), } 46 \% \text { (women) }\end{array}$ \\
\hline Mumford et al $1997^{\text {w14 }}$ & Prospective two stage survey & 664 (both), $\geq 18$ & $\begin{array}{l}\text { BSI- } 44 \text { cut-off }>25, \text { SRQ cut-off }>5 \text {, } \\
\text { ICD } 10 \text { R, SESP }\end{array}$ & $\begin{array}{l}\text { PP of A+D (using BSI-44 and SRQ } \\
\text { (high and middle) scores)=25\% } \\
\text { (men), } 66 \% \text { (women); (using } \\
\text { BSI-44)=23\% (men), } 61 \% \text { (women); } \\
\text { (using SRQ) }=26 \% \text { (men), } 75 \% \\
\text { (women) }\end{array}$ \\
\hline \multicolumn{5}{|c|}{ Patients of traditional or faith healers: } \\
\hline Malik et al $2000^{\text {w11 }}$ & Prospective survey & 100 (both), 0-80 & ICD 10 & $\begin{array}{l}\mathrm{D}=18 \%, \mathrm{GAD}=5 \% \text {. (Men: } \mathrm{D}=6.3 \% \text {, } \\
\mathrm{GAD}=4.2 \% \text {. Women: } \mathrm{D}=28.8 \% \text {, } \\
\mathrm{GAD}=5.8 \% \text { ) }\end{array}$ \\
\hline Saeed et al $2000^{\text {w19 }}$ & Prospective cross sectional survey & 113 (both), No data & $\begin{array}{l}\text { GHQ } 12 \text { cut-off }>1 \text {, psychiatric } \\
\text { interview }\end{array}$ & $\begin{array}{l}P \text { of } D=12.39 \%, P \text { of } A=1.76 \% \text {. } \\
\text { (Men: } D=2.65 \%, A=0 \% . \text { Women: } \\
D=9.73 \% \%, A=1.76 \% \text { ) }\end{array}$ \\
\hline Saeed et al $2000^{\mathrm{w} 20}$ & Prospective two stage survey & 298 (both), No data & GHQ-12 cut-off $>1$, PAS & $\begin{array}{l}\mathrm{D}=24 \% \text { (19 to } 29), \mathrm{GAD}=15 \%(11 \text { to } \\
19), \mathrm{PA}=4 \% \text { (2 to } 7) . \text { Men: } \mathrm{D}=15 \% \\
\text { (8 to } 22), \mathrm{GAD}=6 \% \text { (2 to } 12), \\
\mathrm{PA}=6 \%(2 \text { to } 12) \text {. Women: } \mathrm{D}=29 \% \\
(23 \text { to } 36), \mathrm{GAD}=20 \%(14 \text { to } 25), \\
\mathrm{PA}=3 \% \text { (1 to } 7)\end{array}$ \\
\hline \multicolumn{5}{|l|}{ Primary care sample: } \\
\hline Dodani et al $2000^{\mathrm{w} / 4}$ & Prospective cross sectional survey & 120 (women), 16-60 & Questionnaire, HADS cut-off $>10$ & $\begin{array}{l}P \text { of } A+D=50 \%, D=8.3 \%, A=25 \%, \\
D A=16.7 \% .\end{array}$ \\
\hline \multicolumn{5}{|l|}{ Urban setting } \\
\hline \multicolumn{5}{|l|}{ Population based sample: } \\
\hline Javed $1994^{\mathrm{w} 9}$ & Prospective cross sectional survey & 200 (both), No data & GHQ-30 cut-off $>9$, HADS cut-off $>7$ & $\begin{array}{l}\mathrm{P}=33 \% \text { using } \mathrm{GHQ}-30 \text {, data from } \\
\text { HADS unclear. }\end{array}$ \\
\hline Mumford et al $2000^{\text {w15 }}$ & Prospective two stage survey & 760 (both), $\geq 18$ & BSI-44 cut-off $>20$, ICD10 R & $\begin{array}{l}\mathrm{PP} \text { of } \mathrm{A}+\mathrm{D} \text { (using BSI-44)=10\% } \\
\text { (men), } 25 \% \text { (women) }\end{array}$ \\
\hline Rabbani et al $2000^{w 18}$ & Prospective cross sectional survey & 260 (women), $15-49$ & AKUADS cut-off $>19$, questionnaire & $P C$ of $A+D=28.8 \%$ \\
\hline \multicolumn{5}{|l|}{ Primary care sample: } \\
\hline Ali et al $1993^{w 1}$ & Prospective cross sectional survey & 167 (both), $\geq 16$ & HADS cut-off $>10$ & $\begin{array}{l}\text { PP of } A+D=38.4 \%(A=19.2 \%, \\
D=4.2 \%, D A=15 \%)\end{array}$ \\
\hline Ali et al $2000^{\mathrm{w} 2}$ & Prospective cross sectional survey & 487 (both), 16-65 & $\begin{array}{l}\text { Point prevalence using DSM III R } \\
\text { criteria }\end{array}$ & $\begin{array}{l}\text { P of } A+D=30.4 \% . \text { Men: } A+D=18 \% \\
(A=5 \%, D=5.9 \%, D A=7.1 \%) . \text { Women: } \\
A+D=42.2 \% \quad(A=14.1 \%, D=9.6 \%, \\
D A=18.5 \%)\end{array}$ \\
\hline \multicolumn{5}{|l|}{ Psychiatric outpatients: } \\
\hline Gadit et al $1998^{\mathrm{w} 5}$ & Retrospective case note study & 700 (both), No data & Psychiatric interview & $\mathrm{D}=51.6 \%, A=5.6 \%, P D=9.1 \%$ \\
\hline Gadit $2001^{\mathrm{w} 6}$ & Retrospective case note study & 1430 (both), 0-90 & Psychiatric interview & $\mathrm{D}=51.9 \%, \mathrm{~A}=5.9 \%, \mathrm{PD}=0.8$ \\
\hline Javed et al $1991^{\text {w8 }}$ & Retrospective case note study & 300 (both), No data & Psychiatric interview & $\begin{array}{l}D=21-30 \%, A=5-18 \%, P h=1-3 \% \\
P D=1-15 \% .\end{array}$ \\
\hline \multicolumn{5}{|l|}{ Psychiatric inpatients: } \\
\hline Malik et al $1999^{\text {w10 }}$ & Case register based study & 177 (both), 10-90 & Psychiatric interview & $\mathrm{D}=12.9 \%, \mathrm{~A}=6.2 \%$ \\
\hline Minhas et al $2001^{\text {w12 }}$ & Case register based study & 2620 (both), No data & Psychiatric interview & $\mathrm{D}=37 \%$ \\
\hline
\end{tabular}

Epidemiological terms: $\mathrm{AP}=$ adjusted prevalence, $\mathrm{PC}=$ probable cases, $\mathrm{PP}=$ point prevalence, $\mathrm{P}=$ prevalence.

Disorders: $A+D=$ anxiety and depressive disorders, $A=$ anxiety, $D=$ depression, $D A=$ depression with anxiety, GAD=generalised anxiety disorder, $P A=p a n i c$ disorder (with or without agoraphobia), $\mathrm{Ph}=$ phobias, $\mathrm{PD}=$ psychosomatic disorder.

Scales: AKUADS=Aga Khan University anxiety and depression scale, BSI=Bradford somatic inventory, DSM III-R=Diagnostic and Statistical Manual (3rd ed revised), GHQ=general health questionnaire, HADS=hospital anxiety and depression scale, ICD-10-R=International Classification of Diseases Research Criteria (10th ed), PAS=psychiatric assessment schedule, PHQ=personal

health questionnaire, LEDS=life events and difficulties schedule, SESP=socioeconomic scales for Pakistan, SRQ=self reporting questionnaire.

\section{What is the evidence for effectiveness of treatment or prevention in this population?}

We could not find any prospective study of the natural course of the disorder or any rigorous controlled study addressing effectiveness of treatment and prevention. We found only one randomised controlled trial in mental health, regarding the ability of schoolchildren to detect mental disorders after having been given health education. ${ }^{8}$

\section{Discussion}

In our systematic review we found that socioeconomic adversity and relationship problems were major risk factors for anxiety and depressive disorders in Pakistan, whereas supportive family and friends may protect against development of these disorders.

\section{Limitations of study}

Our review may be subject to publication and selection bias as we were unable to systematically contact the experts in Pakistan for unpublished material or grey literature.

The coverage of the studies we identified is low. Despite detailed searches, we found that most studies satisfying our inclusion criteria were from the provinces of Punjab and Sindh, the two provinces with the largest population in Pakistan. The epidemiological data were collected from a handful of villages and urban settlements. There was considerable methodological 


\begin{tabular}{|c|c|c|c|}
\hline Study & Negative association & Positive association & No association \\
\hline \multicolumn{4}{|l|}{ Population based sample: } \\
\hline Hussain et al $2000^{\mathrm{w} 7}$ & Higher level of education & $\begin{array}{l}\text { Women; unemployment; widowed, separated, or } \\
\text { divorced; } \geq 4 \text { children; loss of a child or father during } \\
\text { childhood; marked independent chronic difficulties } \\
\text { (housing, financial, health) }\end{array}$ & \\
\hline Mumford et al $1996^{\text {w13 }}$ & Higher level of education, higher socioeconomic status & & Life events, joint or nuclear family \\
\hline Mumford et al $1997^{\text {w14 }}$ & $\begin{array}{l}\text { General wealth factor, higher level of education in } \\
\text { younger men and women }\end{array}$ & Age, women living in unitary households & \\
\hline Mumford et al $2000^{\text {w15 }}$ & $\begin{array}{l}\text { Higher level of education especially in young women, } \\
\text { higher socioeconomic variables in women }\end{array}$ & Age, women living in joint households, & \\
\hline Rabbani et al $2000^{\text {w18 }}$ & Husband employed & $\begin{array}{l}\text { Older women, longer duration of marriage, arguments } \\
\text { with husband or in-laws, lack of autonomy }\end{array}$ & Disturbing event in family $(\mathrm{P}=0.08)$ \\
\hline \multicolumn{4}{|l|}{ Primary care sample: } \\
\hline Ali et al $1993^{\text {w1 }}$ & & Women, housewives & Income $(P=0.06)$ \\
\hline Ali et al $2000^{\mathrm{w} 2}$ & Higher level of education & $\begin{array}{l}\text { Women, young adults and late middle age group, } \\
\text { married }\end{array}$ & \\
\hline Dodani et al $2000^{\text {w4 }}$ & Higher level of education & More than 12 members in a single household & Marriage \\
\hline \multicolumn{4}{|c|}{ Secondary and tertiary care sample: } \\
\hline Bender $2001^{\mathrm{w} 3}$ & & $\begin{array}{l}\text { Social problems, relational problems with in-laws } \\
\text { compared with other social problems }\end{array}$ & \\
\hline \multicolumn{4}{|l|}{ Case-control study: } \\
\hline Naeem $1992^{\text {w16 }}$ & & Absence of confiding relationship with husband & $\begin{array}{l}\text { Loss of mother before age } 11, \geq 3 \\
\text { children under age of } 14 \text { at home, } \\
\text { lack of paid employment }\end{array}$ \\
\hline \multicolumn{4}{|l|}{ Qualitative study: } \\
\hline Rabbani 1999w17 & $\begin{array}{l}\text { Social support from talking with husband, health care } \\
\text { provider, friends, or religious leaders }\end{array}$ & $\begin{array}{l}\text { Perceived factors: low family income, marital disputes, } \\
\text { verbal abuse by in-laws, too many children }\end{array}$ & \\
\hline
\end{tabular}

variation in study design and in the instruments used. Thus one is unable to extrapolate these epidemiological findings to the whole of Pakistan.

\section{Comparison with other low income countries}

Using stringent criteria, Harding et al reported an overall frequency of anxiety and depression of 13.9\% in four developing countries. ${ }^{9}$ Community studies from Africa have reported prevalences of 24\% in rural Uganda and 20\%-24\% in rural South Africa. Among patients attending primary care, the prevalence varied from $8 \%$ to $29 \%$. Patients attending primary care in India showed prevalences between $21 \%$ and $57 \%{ }^{1}$

In relation to risk factors, Abas and Broadhead found a significant association with formal employment, below average income, overcrowding, and certificate of secondary education in urban Zimbabwe. ${ }^{10}$ In the same study, they also found a significant association with humiliation or entrapment and with death or other loss. ${ }^{11}$ Bhagwanjee in rural South Africa found a significant association with age (risk increasing with age, to a maximum among people aged 30-39 years), single marital status, unemployment, low income, and low educational level. ${ }^{12}$ Similar risk factors were found in studies from Pakistan. However, we found that the reported overall rates were higher in Pakistan and higher among rural than urban populations compared with the above studies. The question is whether these differences are an artefact of measurement or are because of specific factors operating in Pakistan.

\section{Possible reasons for our findings}

Pakistan's population has been exposed to sociopolitical instability, economic uncertainty, violence, regional conflict, and dislocation for at least the past three decades. ${ }^{13}$ These are risk factors for psychiatric disorders ${ }^{3}$ and may help explain the findings of this review.

As in many other countries, women in Pakistan generally have higher rates of illness than men. In a recent study, the main health problems reported by women were mental tension leading to headache and white vaginal discharge leading to body pains and fatigue. ${ }^{14}$ In another study, most women perceived that financial, interpersonal, and family problems were causative or contributory factors in their ill health. They also linked their health to broader social institutions and cultural norms and expectations regarding women's roles and relationships between family members. ${ }^{15}$

\section{The need for stronger evidence and improved research capacity}

The argument that health will automatically improve with economic growth is not supported by the current evidence. Diseases will not go away without specific investments in health interventions. ${ }^{3}$ A coherent mental health policy with a strategic implementation plan is essential for countries that wish to enhance their social, economic, and social capital. ${ }^{16}$

A major obstacle in formulating effective health policy is the lack of robust epidemiological research in Pakistan. ${ }^{17}$ Our review highlights the absence of survey evidence and data from wider regions of Pakistan with regard to anxiety and depression, and the lack of outcome studies and prevention and treatment trials. The time is right for Pakistan to build on this research effort by increasing investment in research capacity. It would also be helpful to have a national epidemiological survey of mental disorders. Such surveys are useful to assess the needs of the population, document the use of existing services, obtain valid information on prevalence and associated risk factors, and monitor the health of the population and trends. ${ }^{16}$

\section{Conclusion}

Available evidence suggests a major social cause for anxiety and depressive disorders in Pakistan, and an overall prevalence of 34\%. This evidence is limited because of methodological problems. Nationally representative psychiatric morbidity surveys and controlled treatment trials are required to inform policy in order to control morbidity from anxiety and depressive disorders.

Contributors: IM proposed the idea, which was further developed by RJ. IM performed the literature search and data extraction. IM and RJ both wrote the paper. IM is guarantor for the study. 


\section{What is already known on this subject}

Anxiety and depressive disorders are associated with considerable economic burden

These disorders represent an emerging public health threat in low income countries

\section{What this study adds}

In Pakistan relationship problems, financial difficulties, and low educational level are positively associated with anxiety and depressive disorders, whereas having a supportive relationship is negatively associated

Systematically collected, peer reviewed evidence suggests an overall prevalence of $34 \%$ for anxiety and depressive disorders in this population, but this finding must be treated with caution because of methodological limitations

Nationally representative psychiatric morbidity surveys and controlled treatment trials are needed to inform policy in order to control morbidity from anxiety and depressive disorders in Pakistan

Funding: None.

Competing interests: None declared.

Ethical approval: Not required.

1 Institute of Medicine. Neurological,psychiatric, and developmental disorders:meeting the challenge in the developing world. Washington, DC: National Academy Press, 2001. (http://books.nap.edu/catalog/10111.html)

2 Murray C, Lopez A. The global burden of diseases: a comprehensive assessment of mortality Murray C, Lopez A. The global burden of diseases: a comprehensive assessment of mortality
and disability from diseases, injuries and risk factors in 1990 and projected to 2020. Boston: Harvard School of Public Health, WHO and World Bank, 1996.
3 World Health Organization. Macroeconomics and health: investing in health for economic development. Geneva: WHO, 2001 (http://www3.who.int/whosis/menu.cfm?path= whosis, $\mathrm{cmh} \&$ language $=$ english),

4 Desjarlis R, Eisenberg L, Good B, Kleinman A. World mental health:problems and priorities in low-income countries. Oxford: Oxford University Press, 1995.

5 Population Division, Department of Economic and Social Affairs, United Nations Secretariat. U.N. The world at six billion (ESA/P/WP.154). Part 2-Table 5-8. New York: UN, 1999: 12-22. (www.un.org/esa/population/publications/sixbillion/sixbilpart2.pdf)

6 Greenhalgh T. How to read a paper: the basics of evidence based medicine. London: BMJ Publishing Group, 1999.

7 Mirza I. Common mental disorders in urban v rural Pakistan. Br J Psychiatry 2001;178:475-6

8 Rahman A, Mubbashar M, Gater R, Goldberg D. Randomised trial of impact of school Rahman A, Mubbashar M, Gater R, Goldberg D. Randomised trial of impact of schoo
mental-health programme in rural Rawalpindi, Pakistan. Lancet 1998;352:1022-5.

9 Harding TW, de Arango MV, Baltazar J, Climent CE, Ibrahim HH, Ladrido-Ignacio L, et al. Mental disorders in primary health care: a study of their frequency and diagnosis in four developing countries. Psychol Med 1980;10:231-41.

10 Abas M, Broadhead J. Depression and anxiety among women in an urban setting in Zimbabwe. Psychol Med 1997;27:59-71.

11 Broadhead J, Abas M. Life events, difficulties and depression among women in an urban setting in Zimbabwe. Psychol Med 1998;28:29-38.

12 Bhagwanjee A, Parekh A, Paruk Z, Petersen I, Subedar H. Prevalence of minor psychiatric disorders in an African rural community in South Africa. Psychol Med 1998;28:1137-47.

13 Mehmood S. Pakistan: political roots and development 1947-1999. Oxford: Oxford University Press, 2000.

14 Winkvist A, Akhtar H. Images of health and health care options among low income women in Punjab, Pakistan. Soc Sci Med 1997;45:1483-91.

15 Tareen E. The perception of social support and the experience of depression in Pakistani women [PhD thesis]. Colchester: University of Essex, 2000.

16 Jenkins R. Making psychiatric epidemiology useful: the contribution of epidemiology to government policy. Acta Psychiatr Scand 2001;103:2-14.

17 Baig L. Why epidemiological research in Pakistan? J Pak Med Assn 2001;51:206.

$$
\text { (Accepted } 5 \text { March 2004) }
$$

bmj.com 2004;328:794

Royal London Hospital (St Clement's), London E3 4LL Ilyas Mirza specialist registrar in adult psychiatry

WHO Collaborating Centre for Mental Health, Institute of Psychiatry, London SE5 8AF

Rachel Jenkins visiting professor and director

Correspondence to: I Mirza, Larkswood Centre, Thorpe Coombe Hospital, London E17 3HP ilyasmirza@blueyonder.co.uk 